\title{
Risk factors for myocardial infarction and death in newly detected NIDDM: the Diabetes Intervention Study, 11-year follow-up
}

\author{
M. H anefeld ${ }^{1}$, S. Fischer ${ }^{1}$, U . J ulius ${ }^{1}$, J. Schulze ${ }^{1}$, U . Schwanebeck ${ }^{1}$, H . Schmechel ${ }^{2}$, H . J .Z iegelasch ${ }^{3}$, J .L indner ${ }^{4}$, \\ The DIS G roup \\ ${ }^{1}$ M edical Faculty C.G.Carus, Technical U niversity D resden, D resden, G ermany \\ ${ }^{2} \mathrm{D}$ istrict Hospital Weimar, Weimar, Germany \\ ${ }^{3} \mathrm{D}$ istrict H ospital Schwerin, Schwerin, G ermany \\ ${ }^{4} \mathrm{D}$ istrict H ospital Chemnitz, Chemnitz, Germany
}

Summary The Diabetes I ntervention Study (DIS) is a prospective population-based multicentre trial of newly detected cases of non-insulin-dependent diabetes mellitus (NIDDM). This report analyses the risk factors for subsequent coronary heart disease and all-cause death during the 11-year follow-up. The prognostic significance of the categories of the NIDDM Policy Group was validated with respect to the incidence of coronary heart disease and mortality. A t baseline 1139 subjects, aged 30-55 years at the time of diabetes detection and classified as diet controlled after a 6-week screening phase, were included. Of the patients $112(15.2 \%)$ suffered from myocardial infarction, 197 (19.82\%) of 994 had died. The odds ratio for all-cause mortality compared to the general population for males at the age of 3645 years was 5.1 and for females 7.0. In multivariate analysis age, blood pressure and smoking were independent risk factors for myocardial infarction and male sex, age, blood pressure, triglycerides, postprandial blood glucose and smoking for death, respectively. The categories of the NIDDM Policy Group target parameters for blood glucose, triglycerides and blood pressure were significant predictors of both CHD and death. Thus, it appears that in NIDDM good control of blood glucose, blood pressure and triglycerides is associated with a lower incidence of coronary heart disease and death rate respectively. [D iabetologia (1996) 39: 1577-1583]

Keywords Non-insulin-dependent diabetes mellitus, coronary heart disease, mortality, risk factors, quality of metabolic control.
Non-insulin-dependent diabetes mellitus (NIDDM) is characterized by an excessive incidence of myocardial infarction (MI) [1-3] and a shortening of life-expectancy by $5-10$ years $[4,5]$. There is a large amount of epidemiological data to show that coronary heart disease (CHD) is the major cause of death in NIDDM $[6,7]$. Prospective studies have shown that the major risk factors for MI in non-diabetic subjects

Corresponding author: Professor M. H anefeld, Institute and Outpatient Clinic for Clinical Metabolic Research, Universitätsklinikum "C.G.Carusi" der TU, Fetscherstrasse 74, D01307 D resden, G ermany

A bbreviations: DIS, D iabetes Intervention Study; CHD, coronary heart disease; NIDDM, non-insulin-dependent diabetes mellitus; MI, myocardial infarction; WHO, World Health O rganisation; I-ECG, ischaemic ECG abnormalities; CI, confidence interval. also operate in NID D M [8-10]. H owever, as demonstrated by Stamler et al. [11] established risk factors such as high serum cholesterol and blood pressure bear a two-to-four times higher risk than in non-diabetic subjects. So far, little is known about the impact of control of hyperglycaemia and various risk factors on the incidence of $\mathrm{MI}$ and mortality in prospective studies in newly detected cases of NID D M $[12,13]$.

In 1990 the European N ID D M Policy G roup published recommendations for quality control of diabetes and associated risk factors with arbitrarily defined cut-off limits for the categories good, borderline and poor [14] of the major determinants for late complications. So far, to our knowledge, the discriminative power and relevance of these categories has not been validated by long-term studies on NIDDM .

The Diabetes Intervention Study (DIS) is a prospective multicentre trial of newly diagnosed 
NID D M patients [15]. In the first phase 1139 subjects classified as diet controlled were randomly allocated to control subjects with "usual" care in diabetes outpatient clinics (I), intensified health education plus placebo (II) and intensified health education plus $1.6 \mathrm{~g}$ clofibric acid/day (III). In the 5-year follow-up no significant effect of intervention measures on both endpoints could be observed when we compared control subjects with usual care in diabetes outpatient clinics with the two intervention subgroups [16]. Thus, both well controlled and poorly controlled patients can be found in the three subgroups. R egardless of the reasons why intervention failed to reduce the incidence of MI and excess mortality in the DIS cohort, the study offers a good opportunity to evaluate the relationship between quality of glucose control and level of coronary risk factors, and these end points. The 11-year follow-up data of a large newly detected NIDDM population is contained within this report which addresses the following: 1) prognostic significance of risk factor level at diabetes detection for both endpoints. 2) The relevance of the categories of quality assurance as recommended by the E uropean NIDD M Policy G roup [14] by means of a retrospective approach linking classification at entry, and then after 2 years' participation in the trial, with incidence of $\mathrm{MI}$ and all-cause mortality.

\section{Subjects and methods}

B ased on centralised registration in the former $\mathrm{E}$ ast G ermany, each subject with a newly detected fasting blood glucose over $7.21 \mathrm{mmol} / \mathrm{l}$ at the age of 30-55 years was considered from the 16 diabetes outpatient clinics working in cooperation with the study. A diagnosis of diabetes was accepted if fasting blood glucose was over $8.88 \mathrm{mmol} / \mathrm{l}$ on a repeat blood test. If fasting blood glucose was between 7.21 and $8.88 \mathrm{mmol} / \mathrm{l}$ a $50 \mathrm{~g}$ oral glucose tolerance test was performed to confirm the diagnosis. The cut-off limits for diabetes were blood glucose value of over $12.21 \mathrm{mmol} / \mathrm{l}$ at $60 \mathrm{~min}$ and over $8.32 \mathrm{mmol} / \mathrm{l}$ at $120 \mathrm{~min}$ [17].

We recruited 1846 diabetic patients in this way, and they underwent a screening phase of 6 weeks with conventional diet and advice on lifestyle modification (Fig. 1). Inclusion criteria were age 30 - 55 years, acceptable glucose control by diet (postprandial blood glucose $<13.87 \mathrm{mmol} / \mathrm{l}$ at follow-up after 4 and 6 weeks on diet) and informed consent to take part in the study. Important exclusion criteria were preexisting $\mathrm{MI}$, stroke, gangrene, cancer and other severe life-threatening diseases, unsatisfactory diet, no consent being given. A ngina pectoris was not an exclusion criterion. Details of recruitment, study design and methods have been described elsewhere [16].

Of the original 1846 subjects, 1139 patients fulfilled the criteria and were willing and able to participate. The minimum follow-up time (except death and drop-outs) was 11 years; average follow-up $12 \pm 2.3$ years. The study was completed by 994 patients $(88.9 \%)$ with at least baseline information available, $197(19.82 \%)$ documented deaths inclusive. In 169 cases $(85.8 \%)$ the cause of death was obtained from death certificates, in 28 cases $(14.2 \%)$ it is unknown. In this report the following exclusions were made: drop-outs ( $n=145)$, ECG

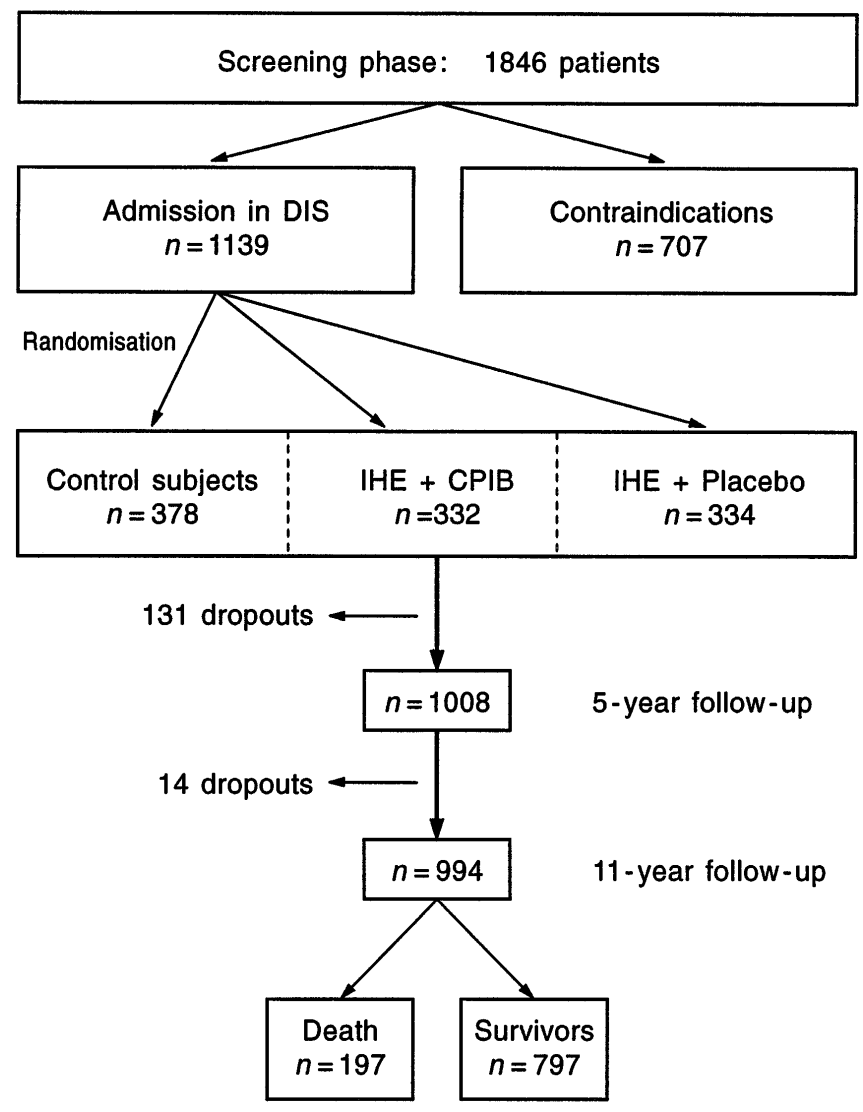

Fig. 1. Patients' recruitment and fate during 11-year follow-up. $I H E$, intensified health education; CPIB , clofibric acid

missing or not in time ( $n=204$ ). The distribution on different treatment regimens at final examination for 797 valid cases was as follows: insulin $32.5 \%$, sulphonylureas $42.2 \%$ and diet $25.3 \%$.

$\mathrm{L}$ aboratory methods and definitions. Blood samples were obtained in the morning following a $12-14 \mathrm{~h}$ fast. Fasting blood glucose, cholesterol and triglycerides were measured as described [16]. Postprandial blood glucose at entry was determined $1 \mathrm{~h}$ after the patient's normal breakfast at visit 2 during the 4th week of the screening phase. $H$ ypertension was diagnosed by World Health O rganisation (WHO) criteria ( $\geq 160$ / $95 \mathrm{mmHg}$ and/or intake of antihypertensive drugs at entry). Smoking was defined as regular consumption of at least one cigarette per day. The categories good, borderline and poor for blood glucose level, triglycerides, cholesterol, blood pressure and BMI were according to the cut-off limits of the NIDDM Policy Group [14].

Endpoints were defined as ischaemic ECG abnormalities (I-E CG ), M Is and death during the study. No CHD (group A ) was assumed if at the final ECG examination no E CG changes indicative for ischaemic heart disease were observed. Patients with newly detected ECG changes according to M innesota codes $1.3,4.1-4.3,5.1-5.3$ or 7.1 during the final examination were considered as having ischaemic E CG abnormality (group $B$ ). Clinical MIs were continuously registered by DIS physicians in co-operation with local hospitals and acute coronary care units. The diagnosis of M I (group C) was accepted when: confirmed by autopsy; established at a hospital on the basis of a diagnostic E CG ; with raised enzyme levels accompanying a typical heart attack (WHO criteria); or when a Minnesota 
Table 1. Baseline characteristics of study population $(n=$ 1139) at entry after 6 weeks on diabetes diet

\begin{tabular}{|c|c|c|}
\hline & M ean & $\begin{array}{l}\text { Confidence } \\
\text { interval }\end{array}$ \\
\hline Sex (male/female \%) & $55.8 / 44.2$ & \\
\hline A ge (years) & 46.7 & $46.3-47.0$ \\
\hline Smokers & $33.9 \%$ & \\
\hline $\begin{array}{l}\text { Fasting blood glucose } \\
(\mathrm{mmol} / \mathrm{l})\end{array}$ & 7.26 & 7.15-7.39 \\
\hline $\begin{array}{l}\text { Postprandial blood glucose } \\
\text { ( } \mathrm{mmol} / \mathrm{l})\end{array}$ & $8.38^{a}$ & $8.24-8.52$ \\
\hline Cholesterol (mmol/l) & 5.74 & $5.66-5.82$ \\
\hline Triglycerides (mmol/l) & 1.97 & $1.88-2.06$ \\
\hline Systolic BP (mm H g) & 149.8 & $148.6-151.0$ \\
\hline D iastolic BP (mm Hg) & 90.5 & $89.8-91.1$ \\
\hline B ody mass index $\left(\mathrm{kg} / \mathrm{m}^{2}\right)$ & 29.2 & $28.9-29.4$ \\
\hline
\end{tabular}

$\mathrm{BP}, \mathrm{Blood}$ pressure; ${ }^{\mathrm{a}} 1 \mathrm{~h}$ after breakfast, week 4 of screening

code 1.1 and/or 1.2 was newly detected at the final E CG examination. Deaths (total mortality) were all documented cases within the observation period.

\section{Statistical analysis}

D ata analysis was performed with the SPSS for Windows and the SPSS/PC + programmes. D ata are given as means and their $95 \%$ confidence intervals $(\mathrm{Cl})$. Two-tailed Student's t-test or the one-way analysis of variance were used in the assessment of the difference between two or more groups when appropriate. Incidence rates were compared by chi square tests. The Kaplan-M eier method was used to construct life-table plots and hazard functions. Discriminant analysis is the statistical technique to find parameters which separate different patient groups.

\section{Results}

Table 1 presents the baseline characteristics of the study population at entry. A that time the patients had undergone a 6-week screening phase with conventional diabetes diet and advice on lifestyle

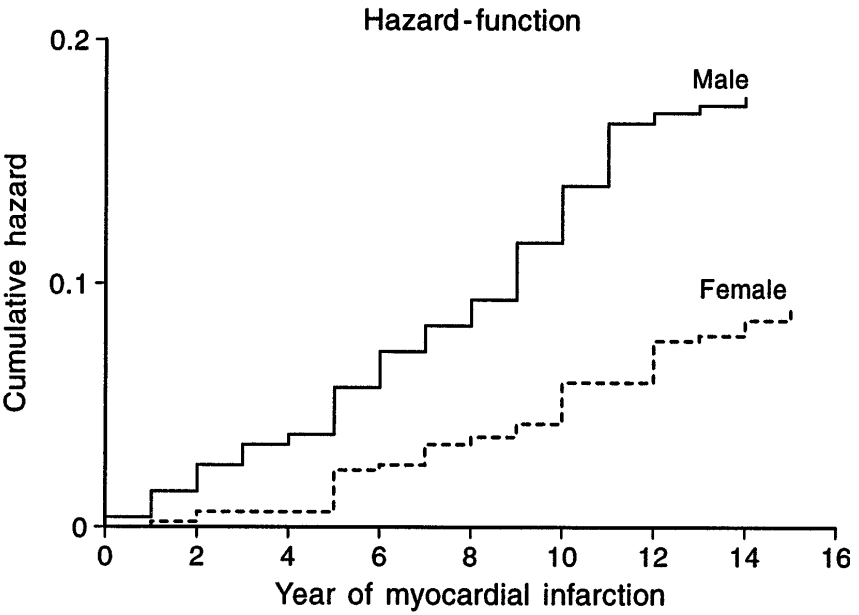

Fig. 2. Cumulative incidence of myocardial infarction by sex (K aplan-M eier function)

improvement; these patients were classified as diet controlled. A s shown in Figure 2 the incidence of $\mathrm{MI}$ by sex was higher among men than among females. The vast majority of MIs occurred after the first 5 years following the detection of diabetes with a particularly low rate among females during the early phase after diagnosis. Table 2 displays the mean values of blood glucose and various risk factors by subsequent development of I-ECG and MI during the observation period. In univariate comparison male sex, age, current smoking, overweight, blood pressure and triglycerides but not cholesterol were significant risk factors for subsequent occurrence of CHD in the 11-year follow-up observation period. Figure 3 demonstrates the excessive mortality of these middle-aged, presumably mild NIDDM patients. A gain male sex carries a higher hazard. There is a striking similarity of risk factors for $\mathrm{MI}$ and death with respect to the risk parameters at entry (Table 3 ). R emarkably, NIDDM patients who died had significantly higher postprandial blood glucose levels during the screening phase whereas fasting blood glucose was not significantly higher. M ultivariate analysis revealed age, blood pressure and smoking at baseline

Table 2. B aseline data of newly detected NIDDM by subsequent I-E CG changes (G roup B), MI (Group C) or normal ECG at 11-year follow-up examination (Group $A$ )

\begin{tabular}{|c|c|c|c|c|c|c|c|}
\hline & \multicolumn{2}{|c|}{ Without IHD $(n=441)$} & \multicolumn{2}{|c|}{ IHD $(n=185)$} & \multicolumn{2}{|c|}{ Infarction $(n=112)$} & \multirow[t]{2}{*}{$p$ value } \\
\hline & M ean & $\mathrm{Cl}$ & M ean & $\mathrm{Cl}$ & M ean & $\mathrm{Cl}$ & \\
\hline Sex (male/female \%) & $62.2 / 56.0$ & & $19.8 / 33.1$ & & $18.0 / 10.9$ & & $<0.01$ \\
\hline Smokers (\%) & 33.9 & & 31.4 & & 45.5 & & $<0.05$ \\
\hline B M I $\left(\mathrm{kg} / \mathrm{m}^{2}\right)$ & 28.4 & $28.0-28.8$ & 29.7 & 29.0-30.4 & 28.7 & 27.9-29.4 & $<0.01$ \\
\hline Fasting blood glucose & 130.5 & $127.2-133.8$ & 130.6 & $125.1-136.1$ & 136.2 & $129.3-143.2$ & NS \\
\hline Postprandial blood glucose & 148.7 & $145.1-152.4$ & 150.5 & $143.9-157.0$ & 158.8 & $150-167.6$ & NS \\
\hline Systolic BP (mm H g) & 146.1 & $144.3-147.8$ & 151.7 & $148.7-154.7$ & 152.9 & $149.1-156.6$ & $<0.01$ \\
\hline D iastolic BP ( $\mathrm{mm} \mathrm{H}$ g) & 88.5 & $87.7-89.4$ & 91.2 & $89.7-92.7$ & 93.3 & $91.2-95.4$ & $<0.01$ \\
\hline
\end{tabular}




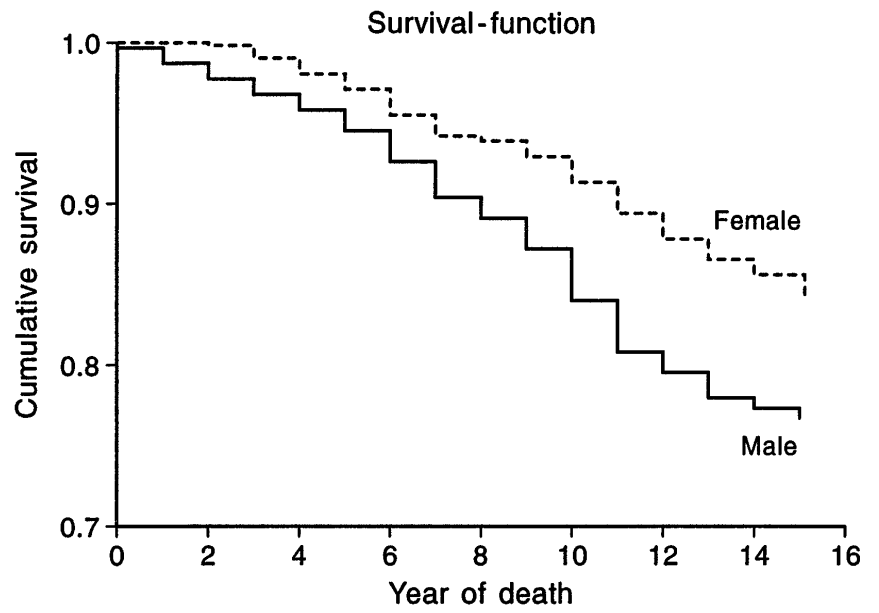

Fig. 3. Kaplan-M eier cumulative function of survival by sex

to be independent risk factors for MI (Table 4). The prognostic significance of postprandial blood glucose, at diabetes detection with regard to life expectancy, was confirmed by multivariate analysis. A nother important predictor of death is hypertriglyceridaemia. However, a high percentage of excessive mortality was not explained by established risk factors, indicated by a correct classification rate of only $62.3 \%$.

Incidence of $\mathrm{MI}$ and mortality according to categories of the E uropean NID D M Policy G roup

The incidence of $\mathrm{MI}$ and death rate, according to quality of metabolic control and level of blood pressure at entry in the study, is shown in Table 5. There was a clear tendency for all parameters classified as poorly controlled to be associated with a higher incidence of MI than those controlled well. This, however, was only significant for postprandial blood glucose and blood pressure. G ood triglyceride and postprandial blood glucose control at baseline were also associated with a lower mortality in the 11-year follow-up observation period. In principle, the same pattern can be observed when the values in the intervention group after a 2-year follow-up (Table 6) are accounted for. This is usually indicative of compliance with the recommended changes in lifestyle and drug treatment. The importance of perfect triglyceride and blood pressure control for survival is confirmed by the low death rate in this category. R egarding mortality, the quality of fasting blood glucose is also a significant discriminator. The excessive mortality in NIDDM is underlined if compared with the age-adjusted death rate in the population (Table 7). The relative risk is particularly high among young females, whereas the absolute risk is distinctly increased for diabetic men compared to diabetic women.

\section{Discussion}

The DIS patients can be considered to be representative of middle-aged, newly detected NIDDM, since they were recruited through a population-based centralised survey of a public health system covering all diabetic patients in diabetes outpatient clinics of the co-operating areas. Taking into account the inclusion and exclusion criteria and excluding patients with preexisting clinical atherosclerotic cardiovasular diseases and the fact that only subjects were included if they were diet controlled they might represent mild to moderate stages of early NIDDM at entry into the study. No significant effect of the intervention measures was established after a 5-year follow-up on these endpoints [16], consequently the pooled evaluation of the 11-year follow-up is justified. The 11-year follow-up data of DIS revealed a high incidence of $\mathrm{CHD}$ in comparison with the general population, illustrating the burden of the disease. In accordance with a report by Barrett-Connor et al. [18] the relatively high hazard of M I in female NIDDM is mainly due to the low incidence among women in the general population, whereas in absolute terms men, including male diabetic patients are at higher risk. In accordance with other reports [19-21] high blood pressure and smoking were significant modifiable risk factors for the subsequent development of CHD. Contrary

Table 3. B aseline characteristics of study population by survival or death during the observation period: $11+$ years follow-up of newly detected NIDDM

\begin{tabular}{|c|c|c|c|c|c|}
\hline & \multicolumn{2}{|c|}{ Survivor $(n=797)$} & \multicolumn{2}{|c|}{ D eceased $(n=197)$} & \multirow[t]{2}{*}{$p$ value } \\
\hline & M ean & $\mathrm{Cl}$ & M ean & $\mathrm{Cl}$ & \\
\hline Sex (male/female \%) & $76.9 / 84.6$ & & $23.1 / 15.4$ & & $<0.01$ \\
\hline Smokers $(\%)$ & 31.6 & & 44.9 & & $<0.01$ \\
\hline Fasting blood glucose ( $\mathrm{mmol} / \mathrm{l})$ & 7.3 & $7.15-7.43$ & 7.5 & $7.25-7.89$ & NS \\
\hline Postprandial blood glucose (mmol/l) & 8.4 & $8.17-8.50$ & 8.9 & $8.52-9.19$ & $<0.01$ \\
\hline Cholesterol $(\mathrm{mmol} / \mathrm{l})$ & 5.7 & $5.63-5.80$ & 5.9 & $5.70-6.09$ & NS \\
\hline Diastolic BP ( $\mathrm{mm} \mathrm{Hg})$ & 90.2 & $89.5-90.9$ & 91.8 & $90.1-91.2$ & NS \\
\hline
\end{tabular}

BP, Blood pressure 
Table 4. M ultivariate analysis of risk factors for $M I(n=108)^{\text {a }}$ and death $(n=187)^{\mathrm{b}}$ in newly detected NID D M : 11 + years follow-up

\begin{tabular}{|c|c|c|c|c|}
\hline \multirow[t]{2}{*}{ Variable } & \multicolumn{2}{|l|}{ MI } & \multicolumn{2}{|l|}{ D eath } \\
\hline & F-value & $p$-value & F -value & $p$-value \\
\hline Sex & & & 8.82 & $<0.01$ \\
\hline A ge & 11.26 & $<0.01$ & 4.70 & $<0.05$ \\
\hline $\begin{array}{l}\text { Systolic blood } \\
\text { pressure }\end{array}$ & & & 8.68 & $<0.01$ \\
\hline $\begin{array}{l}\text { Diastolic blood } \\
\text { pressure }\end{array}$ & 21.22 & $<0.01$ & & \\
\hline Triglycerides & 7.21 & $<0.05$ & 14.02 & $<0.01$ \\
\hline $\begin{array}{l}\text { Postprandial } \\
\text { blood glucose }\end{array}$ & & & 6.11 & $<0.05$ \\
\hline Smoking & 4.18 & $<0.05$ & 7.54 & $<0.01$ \\
\hline
\end{tabular}

Percent of "grouped" cases correctly classified: $64.3 \% \mathrm{MI}$, $62.3 \%$ death.

${ }^{a}$ Baseline values were incomplete for 4 patients. ${ }^{b}$ Baseline values were incomplete for 10 patients

$B P, B l o o d$ pressure

to non-diabetic populations [22] triglycerides were an independent risk factor for $\mathrm{MI}$ in multivariate analysis. The importance of triglyceride levels at disease detection for the fate of NIDDM patients is a consistent finding in all evaluations of our study not only for CHD development but also with respect to allcause and cardiovascular mortality. Santen et al. [23] were the first to demonstrate that hypertriglyceridaemia bears a higher CHD risk for diabetic than for non-diabetic subjects. This is supported by recent reports from the Paris Prospective Study [24] and Finland [25]. There are two possible explanations of why triglycerides are so indicative of MI in NIDDM : (1) hypertriglyceridaemia in diabetic patients is associated with profound alterations in lipoprotein subfraction concentrations and composition, leading to a higher atherogenicity of low density ( $L D L)$ and very low density (VLDL) lipoproteins. For example, small dense LDL particles are increased in NIDDM with hypertriglyceridaemia [26]; (2) hypertriglyceridaemia is indicative of insulin resistance which may be atherogenic. Thus, it appears that the excessive risk of $\mathrm{MI}$ and death is mainly due to the cluster of the metabolic syndrome in NIDDM, with hypertension and hypertriglyceridaemia as the major contributors. This is obviously escalated by poor glycaemic control; postprandial hyperglycaemia was found to be an independent risk factor for death in multivariate analysis. A $n$ important finding is that postprandial hyperglycaemia at that early phase was an independent risk factor whereas fasting blood glucose did not reach statistical significance. 0 ur results suggest that the metabolic syndrome of the early diabetic phase may have a fatal impact on the subsequent risk of coronary heart disease and excessive all-cause mortality. This may explain why interventions in the clinical phase may have had only a weak effect on macroangiopathy and mortality. R ecently published data of the 4S-Study with simvastatin [27] suggest that secondary prevention of coronary heart disease should be possible in diabetic patients by substantial reduction of $L D L$ cholesterol.

The burden of NIDDM is demonstrated by the excessive all-cause mortality of the DIS patients. The relative risk was particularly high in the younger age classes and for females, if compared with vital statistics for the general population in E ast Germany at that time [28] (Table 7). This finding is in accordance with reports from geographically defined diabetes populations by Panzram and Zabel-L anghennig [1]

Table 5. Incidence of MI and mortality according to categories of the NID D M Policy G roup: 11-year follow-up

\begin{tabular}{|c|c|c|c|c|c|}
\hline $\mathrm{R}$ ate per 1000 & & Good & B orderline & Poor & $p$ value \\
\hline $\begin{array}{l}\text { Fasting } \\
\text { blood glucose }\end{array}$ & $\begin{array}{l}\text { MI } \\
\text { M ortality }\end{array}$ & $\begin{array}{l}4.4-6.1 \mathrm{mmol} / \mathrm{l} \\
123 \\
164\end{array}$ & $\begin{array}{l}\leq 7.8 \mathrm{mmol} / \mathrm{l} \\
147 \\
220\end{array}$ & $\begin{array}{l}>7.8 \mathrm{mmol} / \mathrm{l} \\
183 \\
203\end{array}$ & $\begin{array}{l}\text { NS } \\
\text { NS }\end{array}$ \\
\hline Triglycerides & $\begin{array}{l}\text { MI } \\
\text { M ortality }\end{array}$ & $\begin{array}{l}<1.7 \mathrm{mmol} / \mathrm{l} \\
138 \\
161\end{array}$ & $\begin{array}{l}\leq 2.2 \mathrm{mmol} / \mathrm{l} \\
157 \\
238\end{array}$ & $\begin{array}{l}>2.2 \mathrm{mmol} / / \\
180 \\
240\end{array}$ & $\begin{array}{l}\text { NS } \\
<0.05\end{array}$ \\
\hline Cholesterol & $\begin{array}{l}\text { MI } \\
\text { M ortality }\end{array}$ & $\begin{array}{l}<5.2 \mathrm{mmol} / \mathrm{l} \\
120 \\
178\end{array}$ & $\begin{array}{l}\leq 6.5 \mathrm{mmol} / \mathrm{l} \\
156 \\
196\end{array}$ & $\begin{array}{l}>6.5 \mathrm{mmol} / \mathrm{l} \\
199 \\
222\end{array}$ & $\begin{array}{l}\text { NS } \\
\text { NS }\end{array}$ \\
\hline B lood pressure & $\begin{array}{l}\text { MI } \\
\text { M ortality }\end{array}$ & $\begin{array}{l}\leq 149 / 90 \mathrm{~mm} \mathrm{Hg} \\
109 \\
178\end{array}$ & $\begin{array}{l}\leq 160 / 95 \mathrm{~mm} \mathrm{H} \mathrm{g} \\
147 \\
175\end{array}$ & $\begin{array}{l}>160 / 95 \mathrm{~mm} \mathrm{H} \mathrm{g} \\
216 \\
244\end{array}$ & $\begin{array}{l}<0.01 \\
\text { NS }\end{array}$ \\
\hline
\end{tabular}


Table 6. Incidence of MI and mortality according to categories of the NID D M Policy G roup in the Intervention-G roup: values after 2 years' participation in DIS

\begin{tabular}{|c|c|c|c|c|c|c|c|c|}
\hline \multirow[t]{2}{*}{$\mathrm{R}$ ate per 1000} & \multicolumn{4}{|c|}{ M ortality rate } & \multicolumn{4}{|c|}{ Incidence of M I } \\
\hline & Good & B orderline & Poor & $p$ value & Good & Borderline & Poor & $p$ value \\
\hline Fasting blood glucose & 112 & 166 & 233 & $<0.01$ & 117 & 148 & 182 & NS \\
\hline Cholesterol & 145 & 172 & 223 & NS & 114 & 196 & 134 & NS \\
\hline Blood pressure & 133 & 192 & 234 & $<0.05$ & 106 & 159 & 223 & $<0.05$ \\
\hline Body mass index & 175 & 208 & 171 & NS & 115 & 157 & 161 & NS \\
\hline
\end{tabular}

( $n=666 ; 95$ patients without complete information in year 2)

Table 7. A Il-cause mortality $(n / 1000)$ by age and sex in newly detected NIDDM in comparison with the general population: DIS, 11-year follow-up

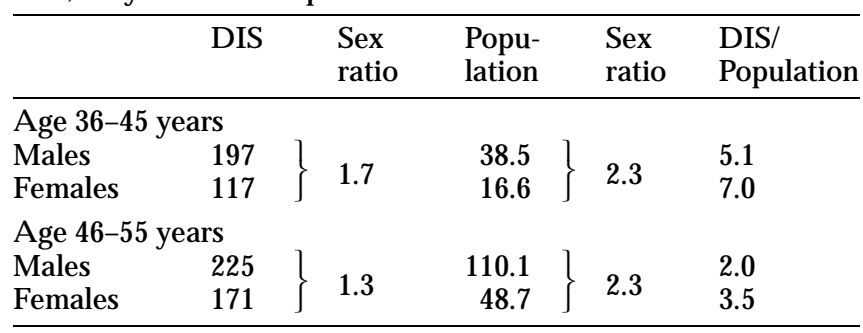

and recent publications from various NIDDM cohorts [18, 20, 29, 30], including elderly patients [31].

To our knowledge the prognostic relevance of the quality categories of the NIDDM Policy Group [14] with respect to macrovascular complications and allcause mortality has not yet been validated in longterm follow-up studies of clearly defined NIDDM. Consistent with previous analysis of risk factors for $\mathrm{MI}$, triglycerides and blood pressure control, even in the first months after diabetes detection, were the most relevant. The central importance of hypertension control in the early phases of diabetes is a consistent finding in most epidemiological studies [2]. A gain the importance of triglyceride control was confirmed if mortality was linked to the target levels of triglycerides at entry in the DIS Study. Furthermore, postprandial blood glucose, though not fasting blood glucose, was a significant predictor of subsequent M I and mortality, demonstrating the crucial importance of strict control of postprandial hyperglycaemia. The gradient between the three categories showing incidence of MI with respect to fasting blood glucose, triglyceride and blood pressure level is even clear in the intervention group. However, it does not reach significance, probably because of the small number of cases. The target levels of blood glucose, triglyceride and blood pressure control have an even better discriminative power with respect to total mortality. If one compares the relevance of the three categories (good, borderline, poor) there is a clear gradient for the frequency of events when linked to quality of target parameters. With respect to triglycerides, however, our results suggest that a lower cut-off limit for "borderline" triglycerides may be useful because mortality was at the same levels in the categories "borderline" and "poorly controlled". A Itogether, as in the case with the multivariate analysis of risk factors there is a striking parallel between predictors of MI and all-cause mortality. Extrapolation and validation of the relevance of the categories of the NIDDM Policy $G$ roup reveals that they are helpful to provide a better definition of the risk of CHD and death for NID D M patients in relation to blood glucose, triglycerides and blood pressure as target parameters. The classification of serum cholesterol and BMI was of no importance in our study.

\section{References}

1. Panzram G, Z abel-L anghennig R (1981) Prognosis of diabetes mellitus in a geographically defined population. $D$ iabetologia 20: 587-591

2. Pyörälä K, Laakso M, U usitupa M (1987) Diabetes and atherosclerosis: A n epidemiologic view. D iabetes $M$ etab R ev 3: 463-524

3. L aakso M, R önnemaa T, L ehto S, Puukka P, Kallio V, Pyörälä K (1995) D oes NID D M increase the risk for coronary heart disease similarly in both low- and high-risk populations? D iabetologia 38: 487-493

4. Pell S, D'A lonzo CA (1970) Factors associated with long term survival of diabetes. J A m M ed A ssoc 214: 1833-1840

5. Panzram G (1987) M ortality and survival in type 2 (non-insulin-dependent) diabetes mellitus. Diabetologia 30: 123131

6. Janka HU, B alletshofer B, B ecker A et al. (1992) D as metabolische Syndrom als potenter R isikofaktor für frühzeitigen Tod bei Typ-II-D iabetikern. D ie Schwabinger Studie II - U ntersuchungen nach 9 Jahren. Diab Stoffw 1: 2-7

7. Standl E, Janka HV, Stiegler H, M ehnert H (1992) Hyperinsulinemia and macrovascular complications in NIDDM. In: Lefebvre PJ, Standl E (eds) N ew aspects in diabetes. Walter de G ruyter, B erlin, NY, pp 87-95

8. U usitupa M, Siitonen O, A ro A, Pyörälä K (1985) Prevalence of coronary heart disease, left ventricular failure and hypertension in middle-aged, newly diagnosed type 2 (non-insulin-dependent) diabetic subjects. Diabetologia 28: 22-27

9. Koskinen $\mathrm{P}, \mathrm{M}$ änttäri $\mathrm{M}, \mathrm{M}$ anninen $\mathrm{V}, \mathrm{H}$ uttunen J K, H einonen OP, Frick M H (1992) Coronary heart disease incidence in NIDD M patients in the Helsinki Heart Study. D iabetes Care 15: 820-825

10. Fuller JH, Shipley MJ, R ose G, Jarrett RJ, K een H (1983) Mortality from coronary heart disease and stroke in 
relation to degree of glycaemia: the Whitehall study. B M J 287: 867-870

11. Stamler J, Vaccaro O, N eaton J, Wentworth D, for the M ultiple R isk Factor Intervention Trial R esearch G roup (1993) Diabetes, other risk factors, and 12-year cardiovascular mortality for men screened in the multiple risk factor intervention trial. D iabetes Care 16: 434-449

12. U usitupa MIJ, Niskanen LK, Siitonen O, Voutilainen E, Pyörälä K (1993) Ten-year cardiovascular mortality in relation to risk factors and abnormalities in lipoprotein composition in type 2 (non-insulin-dependent) diabetic and nondiabetic subjects. D iabetologia 36: 1175-1184

13. UK Prospective Diabetes Study (UKPDS) (1991) VIII. Study design, progress and performance. D iabetologia 34: 877-890

14. A lberti KG MM, Gries FA, Jervell J, K rans $H J M$ for the European NIDD M Policy G roup (1994) A desktop guide for the management of non-insulin-dependent diabetes mellitus (NID D M): an update. D iab M ed 11: 899-909

15. $\mathrm{H}$ anefeld $M, \mathrm{H}$ aller $\mathrm{H}$, Schulze J, J ulius U, Fischer $\mathrm{S}$, R othe G (1984) Die Diabetes-Interventionsstudie (DIS) eine multizentrische Multiinterventionsstudie bei Typ-II-Diabetikern. D t G es Wesen 39: 1889-1894

16. H anefeld M , Fischer S, Schmechel H et al. (1991) D iabetes Intervention Study: Multiintervention trial in newly diagnosed NID D M . D iabetes Care 14: 308-317

17. Michaelis D (1978) Diagnose, D ifferentialdiagnose und Symptomatologie des D iabetes mellitus sowie der $\mathrm{H}$ ypoglykämien. In: Bibergeil $H$ (ed) Diabetes mellitus. VEB G ustav Fischer, Jena pp 79-183

18. Barrett-Connor E, Wingard DL (1983) Sex differential in ischemic heart disease mortality in diabetics: a prospective population based study. A m J Epidemiol 118: 489-496

19. U usitupa M , Siitonen O, Pyörälä K et al. (1987) R elationship of blood pressure and left ventricular mass to serum insulin levels in newly diagnosed non-insulin-dependent (type 2) diabetic patients and in non-diabetic subjects. D iabetes $R$ es 4: 19-25

20. Manson J E, Colditz G A , Stampfer MJ et al. (1991) A prospective study of maturity-onset diabetes mellitus and risk of coronary heart disease and stroke in women. A rch Intern M ed 151: 1141-1147
21. Hypertension in Diabetes Study (HDS) (1993) II. Increased risk of cardiovascular complications in hypertensive type 2 diabetic patients. J H ypertens 11: 319-325

22. West K M, A huja M M S, B ennett PH et al. (1983) The role of circulating glucose and triglyceride concentrations and their interaction with other risk factors as determinants of arterial disease in nine diabetic population samples from the W HO M ultinational Study. D iabetes Care 6: 361-369

23. Santen RJ, Willis PW, Fajans SS (1972) A therosclerosis in diabetes mellitus. Correlations with serum lipid levels, adiposity, and serum insulin level. A rch Intern M ed 130: 833843

24. Fontbonne A, E schwége E , C ambien F et al. (1989) H ypertriglyceridemia as a risk factor for coronary heart disease mortality in subjects with impaired glucose tolerance or diabetes: results from the five year follow-up of the Paris Prospective Study. D iabetologia 32: 300-304

25. L aakso M , L ehto S, Penttila I, Pyörälä K (1993) L ipids and lipoproteins predicting coronary heart disease mortality and morbidity in patients with non-insulin-dependent diabetes. Circulation 88: 1421-1430

26. H affner SM (1995) L ow-density lipoprotein size in patients with NIDDM and the insulin resistance syndrome. In: Schwartz CJ, Born GVR (eds) New horizons in diabetes mellitus and cardiovascular disease. Current Science. L ondon pp 96-102

27. K jekshus J, Pedersen TR (1995) R educing the risk of coronary events: evidence from the Scandinavian Simvastatin Survival Study (4S). A m J Cardiol 76 (9): 64C-68C

28. Das G esundheitswesen der DDR 1979-89 (1990)Institut für M edizinische Statistik und $D$ atenverarbeitung, B erlin

29. Schneider H, L ischinski M, J utzi E (1993) Survival time after onset of diabetes: 29-year follow-up mortality study in a diabetes cohort from a rural district. D iabet M etab 19: 152158

30. Morrish NJ, Stevens LK, Head J, Fuller JH, Jarrett RJ, $\mathrm{K}$ een $\mathrm{H}$ (1990) A prospective study of mortality among middle-aged diabetic patients (the London Cohort of the WHO Multinational Study of Vascular Disease in Diabetics) II: A ssociated risk factors. D iabetologia 33: 542-548

31. Kuusisto J, M ykkäanen L, Pyörälä K, Laakso M (1994) NIDDM and its metabolic control predict coronary heart disease in elderly subjects. D iabetes 43: 960-967 